Cite this: Dalton Trans., 2014, 43, 3897

Received 27th September 2013, Accepted 27th November 2013

DOI: $10.1039 / c 3 d t 52695 j$

www.rsc.org/dalton

\section{One-pot synthesis of iron doped mesoporous silica catalyst for propane ammoxidation}

\author{
Eva Bad'urová, * Kateřina Raabová and Roman Bulánek \\ Iron doped hexagonal mesoporous silica (Fe-HMS) was successfully prepared by one-pot direct synthesis \\ at ambient temperature by using dodecylamine as a templating agent. The catalyst has been characterized \\ by various techniques including XRD, DR-UV-Vis, FTIR, SEM and $\mathrm{N}_{2}$ adsorption. The obtained material \\ exhibits very large surface area (above $1000 \mathrm{~m}^{2} \mathrm{~g}^{-1}$ ), mesoporosity with narrow distribution of pores \\ (around $4 \mathrm{~nm}$ ) and nano-crystallites with the $20-30 \mathrm{~nm}$ in size. The concentration of iron in the catalyst \\ was $0.95 \mathrm{wt} \%$. The prepared material was tested in the direct ammoxidation of propane. It was shown that \\ direct synthesis leads to better dispersion of the metal compared to the material prepared by impreg- \\ nation of pure HMS silica. It is also demonstrated that this material is able to catalyze the direct ammoxi- \\ dation of propane and shows quite high selectivity to acrylonitrile (52\% at $11 \%$ conversion of propane).
}

\section{Introduction}

Iron doped microporous material Fe-MFI and the [Fe]-MFI represent well known and abundantly studied catalytic materials for a variety of industrial reactions, among them for example the selective oxidation of benzene to phenol, ${ }^{1-3}$ the reduction of $\mathrm{NO}_{x}$ and $\mathrm{N}_{2} \mathrm{O}$ with ammonia or hydrocarbons ${ }^{4-9}$ and also the direct decomposition of $\mathrm{N}_{2} \mathrm{O} \cdot{ }^{10,11}$ Although this material reaches very interesting results in the above mentioned reactions, it also suffers from drawbacks connected to the diffusion limitations (due to its microporosity - pore size is $0.51 \times 0.56 \mathrm{~nm})$. In order to overcome these problems several approaches have been proposed and studied. Some of these are: (i) the synthesis of microporous materials with smaller crystal size ${ }^{12}$ or new microporous material with increased pore size $^{13}$ (ii) the preparation of hierarchical materials ${ }^{14,15}$ and (iii) the preparation of mesoporous materials. ${ }^{16}$

In our previous reports we studied microporous systems containing iron species ([Fe]-MFI, [Fe]-MTW) in the direct ammoxidation of propane. ${ }^{17,18}$ These materials were recognized as active and selective catalysts for this reaction only if no strong acid sites were present in the catalyst. It was found that the fast removal of nascent acrylonitrile (ACN) from the catalysts is very important because strong acid sites bind acrylonitrile, substantially increase the residence time of this product and cause its decomposition to acetonitrile and $\mathrm{CO}_{x}{ }^{17}$ Therefore, the best MFI catalyst was Fe-silicalite, a material

Department of Physical Chemistry, Faculty of Chemical Technology, University of Pardubice, Pardubice, Studentska 573, 53210 Czech Republic.

E-mail: eva.badurova@student.upce.cz; Fax: +420 466037068 ; Tel: +420466037052 without strong acid sites (without aluminum in the framework). Another improvement of catalyst behavior was reached by changing the crystallite size. Superior catalytic performance was exhibited by Fe-silicalite characterized by very small size of crystals (about $0.15 \mu \mathrm{m}$ ). The acrylonitrile yield of $12 \%$ and productivity up to $9.3 \mathrm{~mol}_{\mathrm{ACN}}\left(\mathrm{kg}_{\text {cat }} \mathrm{h}\right)^{-1}$ at $540{ }^{\circ} \mathrm{C}$ was obtained over our best catalyst. ${ }^{19}$

This paper reports on the successful synthesis of mesoporous ferrosilicate (Fe-HMS) and its catalytic activity in direct ammoxidation of propane. Such material can benefit from two main advantages (i) as a mesoporous material it should overcome the problems connected with the diffusion, (ii) it contains low amount of strong acid sites even at high concentration of heteroatoms. ${ }^{20}$ The catalytic behavior of Fe-HMS prepared by direct hydrothermal synthesis is compared with a catalyst prepared from hexagonal mesoporous silica by wet impregnation in order to elucidate the effect of iron origin and speciation. In the discussion section, the reported results are compared with our previous results obtained on microporous Fe-silicalite catalysts and discussed in a broader context.

\section{Experimental}

\subsection{Sample preparation}

Two samples of hexagonal mesoporous silica (HMS) structure with different iron content were prepared by different methods - by wet impregnation and by direct synthesis. The preparation process of HMS was described earlier. ${ }^{21}$ It is worth of notice that before the calcination the sample was stirred for 1 hour in ethanol in order to remove the major part of remaining DDA. Subsequently the sample was calcined in a flow of air at $540{ }^{\circ} \mathrm{C}$ 
for $8 \mathrm{~h}$ with heating rate $1^{\circ} \mathrm{C} \mathrm{min}^{-1}$. The sample prepared by impregnation of HMS (denoted as Fe-HMSimp) was synthesized using an aqueous solution of $\mathrm{Fe}\left(\mathrm{NO}_{3}\right)_{3} \cdot 9 \mathrm{H}_{2} \mathrm{O}$. The amount of iron precursor was calculated in order to obtain the material with $c a$. $0.5 \mathrm{wt} \%$ of iron. Impregnation of HMS proceeded below the boiling point of solvent to evaporation of solution. The impregnated sample was dried at $120^{\circ} \mathrm{C}$ in air overnight and then calcined at $600{ }^{\circ} \mathrm{C}$ for 8 hours in a flow of air.

The sample prepared by direct synthesis (denoted as [Fe]HMS) was prepared according to the procedure reported by Liu et l. $^{22}$ The molar composition of this matrix solution was 1.0 $\mathrm{SiO}_{2}$ : $0.006 \mathrm{Fe}\left(\mathrm{NO}_{3}\right)_{3}: 0.27$ DDA : 11 EtOH : 1 i-PrOH : $100 \mathrm{H}_{2} \mathrm{O}$. The mixture was stirred for 24 hours at room temperature; the formed solid was filtered, washed thoroughly with de-ionized water, dried at ambient temperature, directly calcined in nitrogen and after reaching $500{ }^{\circ} \mathrm{C}$ calcined in air for 6 hours to obtain [Fe]-HMS.

\subsection{Sample characterization and catalytic test}

2.2.1 Characterization. The chemical composition of all investigated samples was determined by X-ray fluorescence spectroscopy by ElvaX (Elvatech, Ukraine) equipped with a Pd anode. The structure and crystallinity of catalysts were probed by scanning electron microscopy using a TESCAN MIRA3 FE-SEM instrument and by X-ray diffraction (D8-advance diffractometer, Bruker AXE, Germany) in the low angle $2 \theta$ range of (from 0.2 to $10^{\circ}$ ) and at higher angle range (2-35 $)$ with $\mathrm{Cu} \mathrm{K \alpha}$ radiation $(\lambda=1.5406 \AA)$.

The BET surface area and pore diameter distribution of the samples were determined according to the $\mathrm{N}_{2}$ adsorption isotherms. Nitrogen was used as adsorptive and supplied by Linde (purity 99.999 vol.\%). Sorption isotherms of nitrogen at $77 \mathrm{~K}$ were determined using an ASAP 2020 instrument (Micromeritics, USA) and evaluated by MicroActive Software (Micromeritics, USA). In order to attain a sufficient accuracy in the accumulation of the adsorption data, this instrument is equipped with pressure transducers covering the $133 \mathrm{~Pa}, 1.33$ $\mathrm{kPa}$ and $133 \mathrm{kPa}$ ranges. Before each sorption measurement the sample was degassed to allow a slow removal of the most of preadsorbed water at low temperatures. This was done to avoid potential structural damage of the sample due to surface tension effects and hydrothermal alternation. Starting at ambient temperature the sample was degassed at $110{ }^{\circ} \mathrm{C}$ (temperature ramp of $0.5{ }^{\circ} \mathrm{C} \mathrm{min}^{-1}$ ) until the residual pressure of $1 \mathrm{~Pa}$ was attained. After further heating at $110{ }^{\circ} \mathrm{C}$ for 1 hour the temperature was increased (temperature ramp of $1{ }^{\circ} \mathrm{C}$ $\min ^{-1}$ ) until the temperature of $250{ }^{\circ} \mathrm{C}$ was achieved. The sample was degassed at this temperature under turbomolecular pump vacuum for 8 hours. The specific surface area was calculated according to BET method. The mesopore and external surface area were determined by means of t-plot using Harkins-Jura equation for calculation of adsorbed layer thickness, pore volume and pore size distribution were determined by NL DFT approach by using the "N2 @ 77K" model for cylindrical pores and oxide surface.
The DR-UV-Vis spectra were measured with UV-Vis spectrometer GBC CINTRA 303 equipped with a diffuse reflectance attachment with an integrating sphere coated with spectralon. Pure fumed silica was used as a reference material and samples were diluted with this silica five times before measurements. Absorption intensity was expressed using Schuster-Kubelka-Munk equation.

FTIR spectra were recorded on Nicolet 6700 FTIR spectrometer equipped with an MCT/A cryodetector, accumulating 64 scans at a spectral resolution of $2 \mathrm{~cm}^{-1}$. Self supporting pellets (ca. $10 \mathrm{mg} \mathrm{cm}^{-2}$ ) were prepared from the sample powder and treated directly in a purpose-made IR cell allowing measurements at ambient and liquid nitrogen temperatures. The cell was connected to a vacuum pump allowing a residual pressure $\sim 10^{-4}$ Torr. Before the measurement the samples were treated in reducing atmosphere ( $80 \mathrm{mbar}$ of $\mathrm{H}_{2}$ ) at $450{ }^{\circ} \mathrm{C}$ overnight. Before the adsorption of NO ( $\left.p_{\mathrm{NO}}=0.5 \mathrm{mbar}\right)$, NO was purified by a freezing-thaw cycle in order to avoid the presence of other $\mathrm{NO}_{x}$. Desorption of NO was measured after reaching the equilibrium, which was obtained within 45 minutes. Spectra were collected at different time of desorption at different temperatures (as specified in the caption of figures). The spectrum of dehydrated sample recorded before NO adsorption was subtracted from each spectrum shown in this work.

2.2.2 Catalytic test. Direct ammoxidation of propane was carried out in a plug-flow fixed-bed microreactor at atmospheric pressure. The amount of the catalyst varied in order to have the equal amount of iron $(10 \mu \mathrm{mol} \mathrm{Fe})$ in the loaded catalyst (size of catalyst grains $0.25-0.50 \mathrm{~mm}$ ). The total flow rate was $100 \mathrm{~cm}^{3} \mathrm{~min}^{-1}$, the feed composition was $2.5 \mathrm{vol} \%$ of propane, 5 vol.\% of oxygen and 5 vol.\% of ammonia diluted with helium. The reaction was measured at the temperature of $540{ }^{\circ} \mathrm{C}$. Analysis of the products was made in a TOS (time-onstream) of $50 \mathrm{~min}$. Product gases were analyzed online using GC (Agilent 7890) equipped with TCD and FID detectors. For the analysis of hydrocarbons (propane, propylene and ethane, ethene, methane) a HP PLOT/Q column was used. Permanent gases were analyzed on a HP molsieve column and nitriles were analyzed using a DB-WAX column. Conversion, selectivity and yields were calculated on the basis of the mass balance.

\section{Results and discussion}

\subsection{Characterization}

$\mathrm{N}_{2}$ adsorption isotherms of the impregnated Fe-HMS catalyst together with the parent HMS silica support are displayed in Fig. 1A and textural characteristics are summarized in Table 1. Both isotherms exhibit a very similar shape characterized by a gentle step around a relative pressure of 0.2 and no hysteresis loops evidencing the presence of mesopores with relatively small size. Surface area of parent silica support was $994 \mathrm{~m}^{2} \mathrm{~g}^{-1}$. Impregnation of HMS support by nitrate as a source of iron led to a much more distinct decrease of surface area $\left(795 \mathrm{~m}^{2} \mathrm{~g}^{-1}\right.$, i.e. by about $20 \mathrm{rel} \%$ ), which can be caused by the presence of iron oxide clusters (evidenced by UV-Vis spectroscopy, see 

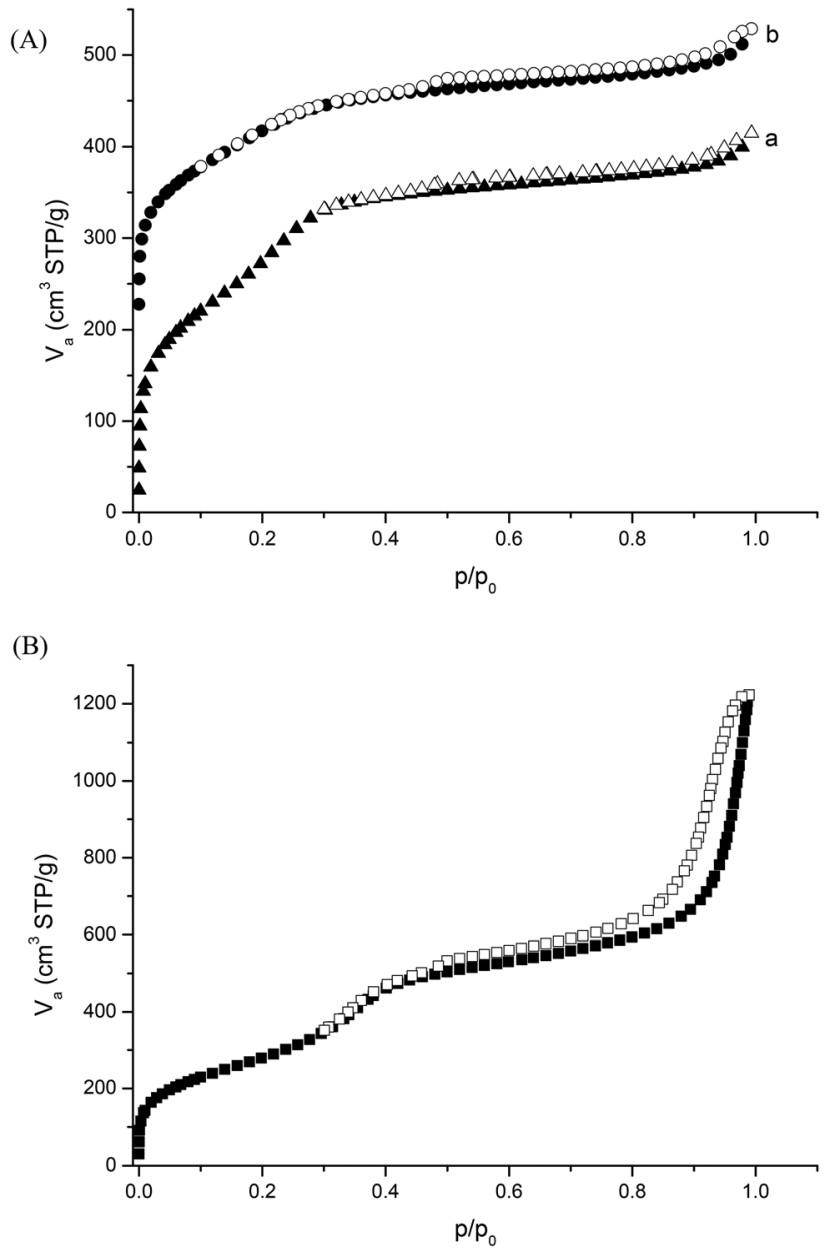

Fig. 1 (A) $\mathrm{N}_{2}$ adsorption/desorption isotherms of parent HMS silica support (a) and impregnated Fe-HMS catalyst (b), (Fe-HMS isotherm is shifted up by $200 \mathrm{~cm}^{3} \mathrm{STP} / \mathrm{g}$ for sake of clarity) (B) $\mathrm{N}_{2}$ adsorption isotherm of [Fe]-HMS.

Table 1 Chemical composition and results of physico chemical characterization of investigated materials

\begin{tabular}{llllll}
\hline Material & $\begin{array}{l}\mathrm{Fe} \\
(\mathrm{wt} \%)\end{array}$ & $\begin{array}{l}S_{\mathrm{BET}} \\
\left(\mathrm{m}^{2} \mathrm{~g}^{-1}\right)\end{array}$ & $\begin{array}{l}S_{\text {ext }} \\
\left(\mathrm{m}^{2} \mathrm{~g}^{-1}\right)\end{array}$ & $\begin{array}{l}V_{\mathrm{p}} \\
\left(\mathrm{cm}^{3} \mathrm{~g}^{-1}\right)\end{array}$ & $d_{\mathrm{p}}(\mathrm{nm})$ \\
\hline HMS & - & 994 & 55 & 0.48 & 3.1 \\
Fe-HMSimp & 0.54 & 795 & 50 & 0.38 & 3.0 \\
[Fe]-HMS & 0.95 & 1033 & 342 & 0.57 & 4.0
\end{tabular}

below) blocking the pores. Indeed, total pore volumes of parent HMS and impregnated Fe-HMS catalyst differ by about 21 rel\% in very good agreement with the decline of surface area. Area of external surface of crystallites determined from t-plots (t-plot for parent HMS is displayed in Fig. 2A, t-plot of impregnated Fe-HMS catalyst is not reported here for the sake of brevity) was found to be 55 and $50 \mathrm{~m}^{2} \mathrm{~g}^{-1}$ for parent HMS and impregnated Fe-HMS, respectively. Such relatively large values are in line with non-compact crystallites with some macroporosity evidenced by SEM (see Fig. 4). Neither parent nor impregnated Fe-HMS catalyst exhibits microporosity as is
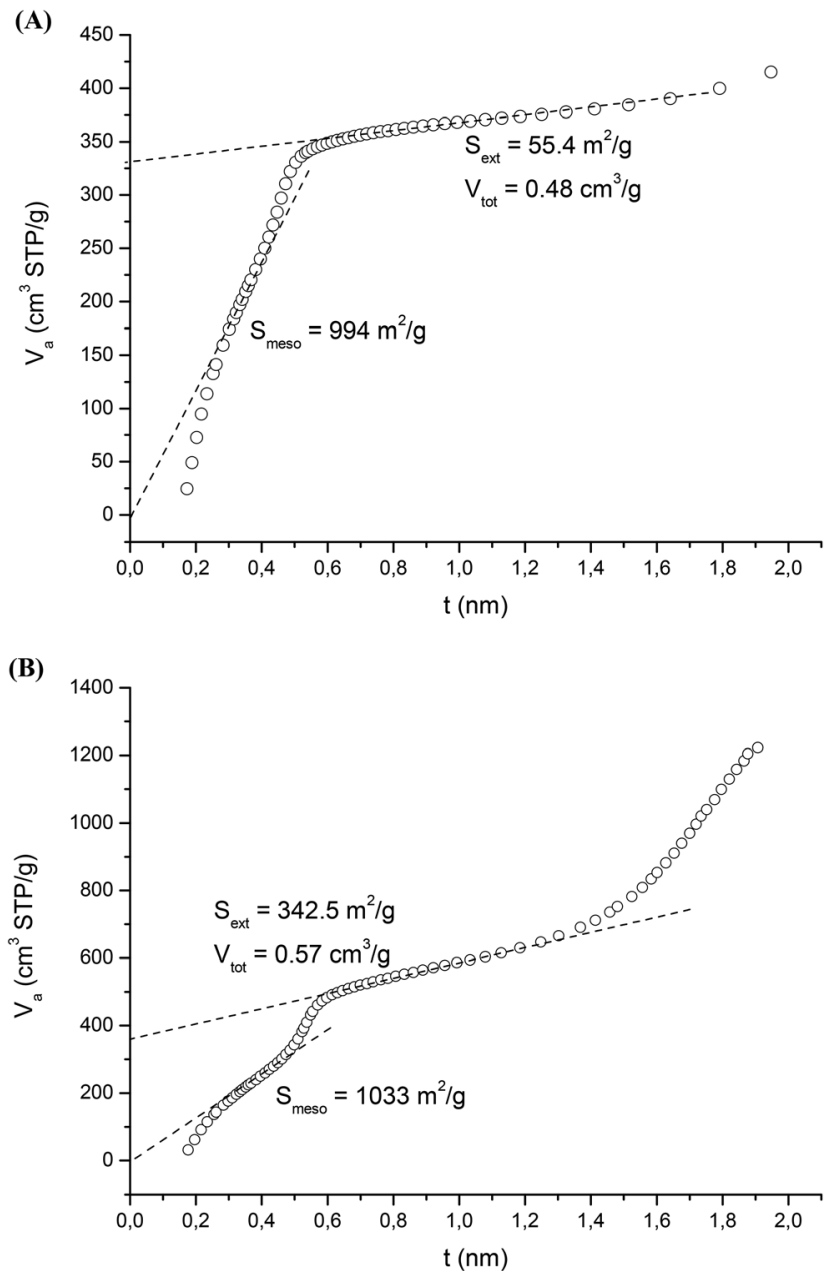

Fig. 2 t-plots constructed by means of Harkins-Jura equation from the isotherm of parent HMS (A) and [Fe]-HMS (B).

manifested by the zero intercept of the straight line fitted BET range of t-plot ( $\mathrm{t}$ ranging from 0.35 to $0.5 \mathrm{~nm}$ ). The texture of the catalyst prepared by direct synthesis exhibits significant differences (see Fig. 1B). Massive condensation of nitrogen, manifested by a sharp increase of the adsorbed amount at relative pressures above 0.9 , indicates the presence of large mesopores/macropores or interparticle adsorption and condensation. SEM images (see Fig. 4) clearly show crystallites with size around $20-30 \mathrm{~nm}$, which agrees well with the characteristics of the adsorption isotherm. Therefore, an extremely high amount of adsorbed nitrogen at relative pressures above 0.9 is caused by condensation in interparticle void space. The nanosize of crystallites is also confirmed by the determination of the external surface area from t-plot which was found to be $342 \mathrm{~m}^{2} \mathrm{~g}^{-1}$ (see Fig. 2B), whereas the total surface area determined by BET method is $1033 \mathrm{~m}^{2} \mathrm{~g}^{-1}$. The size of the pores determined from the isotherms by NL DFT method ranges from 2 to $5 \mathrm{~nm}$ (see Fig. 3) with the main maximum at $3.1 \mathrm{~nm}$ for HMS parent and impregnated sample and $4 \mathrm{~nm}$ for synthesized [Fe]-HMS catalyst. The pore size distribution (PSD) curve of the synthesized catalyst exhibits a narrower peak 


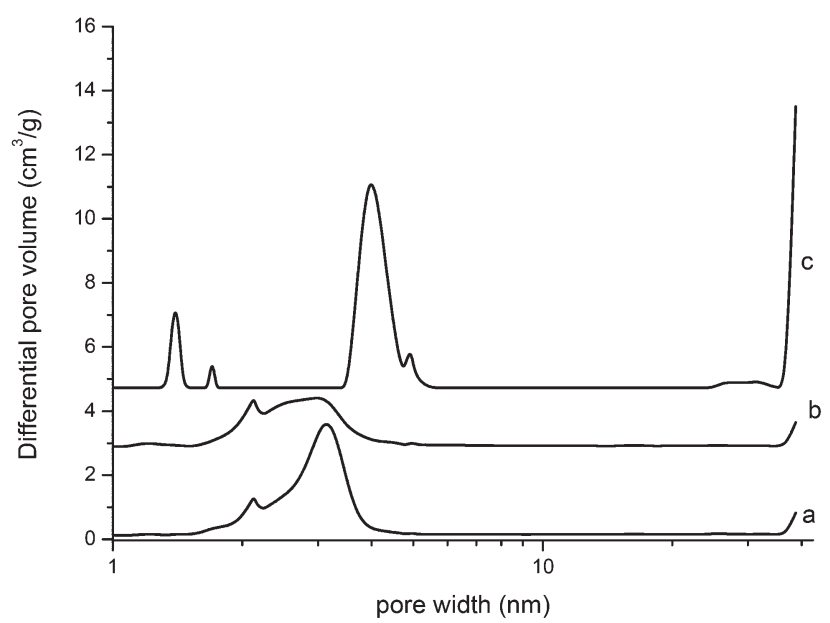

Fig. 3 Pore size distribution calculated from the isotherms displayed in Fig. 1 by NL DFT method for parent HMS silica support (a), impregnated Fe-HMS catalyst (b) and synthesized [Fe]-HMS catalyst (c).

compared with the PSD curves of silica HMS and impregnated samples. It is necessary to note that the total pore volume of synthesized [Fe]-HMS sample is also significantly larger than the total pore volume of parent silica HMS and therefore also than impregnated Fe-HMS catalyst ( $c f$. data in Table 1).

Fig. 4 reports the scanning electron micrographs of parent HMS, of impregnated HMS and of the sample prepared by the direct synthesis [Fe]-HMS. Micrographs of HMS and FeHMSimp are quite similar showing spherical particles with a wide range of macropore crevices. The size of these particles is in a range from 0.5 to $1 \mu \mathrm{m}$. As can be seen from the micrograph, these particles form larger aggregates. The micrograph of the sample [Fe]-HMS shows that the particles are considerably smaller, being about $20-30 \mathrm{~nm}$ in size. The shape of the particles is markedly different from the previous ones, showing rather worm-like structure.

XRD patterns of a parent HMS and Fe-HMS samples (Fig. 5) show a broad low-angle diffraction peak at $2 \theta=2-3^{\circ}(100)$ with poorly resolved satellite at around $5^{\circ}$, which is typical for hexagonal lattice structure of mesoporous materials. ${ }^{22}$ The $d_{100}$ distance determined from the position of the main diffraction peak by means of Bragg's law varies between 3.2 and $3.5 \mathrm{~nm}$ in good agreement with data from the pore size distribution and indicates a relatively thin channel wall. The wide angle region does not show any diffraction peaks of crystalline iron oxides. Possibly, the particles of iron oxides formed upon the impregnation of HMS (see the results from UV-Vis spectroscopy) are too small, amorphous or in very low amount to be detected by X-ray diffraction.

In order to obtain more information about the presence of different iron species located in the structure of HMS of both Fe-HMS samples, the adsorption of nitric oxide was studied by means of FTIR spectroscopy. The adsorption of NO on Fe-containing systems is a very often used method for the characterization of $\mathrm{Fe}$ species $^{23-25}$ (especially in connection with IR spectroscopy). Most authors agree that (di)nitrosyls are formed exclusively with the participation of $\mathrm{Fe}^{2+}$ ions because $\mathrm{NO}$ adsorption on oxidized samples is negligible. ${ }^{26}$ Therefore, samples were reduced (in $80 \mathrm{mbar}_{2}$ ) at $450{ }^{\circ} \mathrm{C}$ during the night before the adsorption. It must be noted that NO adsorption on oxidized samples was measured too and only a very weak band was detected in agreement with literature. Due to negligible NO adsorption on oxidized samples, only the spectra on reduced samples are presented and discussed here.

The IR spectra of NO adsorbed on Fe-HMS samples are shown in the Fig. 6 and 7. Spectra contain a main band centered at about $1820 \mathrm{~cm}^{-1}$. The vibration of $\mathrm{N}-\mathrm{O}$ bond is significantly shifted to lower wavenumber considering frequency of free gaseous NO $\left(1876 \mathrm{~cm}^{-1}\right)$. It is evidence of $\pi$-back bond formation typical for metals with higher density of d-electrons and lower oxidation state. A detailed inspection of the spectra reveals distinct asymmetry of the band with a tail at high-frequency side. This is caused by the overlapping of two bands with the maxima approximately at 1820 and $1836 \mathrm{~cm}^{-1}$. The comparison of normalized envelope curves (see Fig. 7A) clearly shows that the tail is more intense in the case of sample [Fe]HMS. To obtain further information, the desorption of NO from the samples under dynamic vacuum at RT and

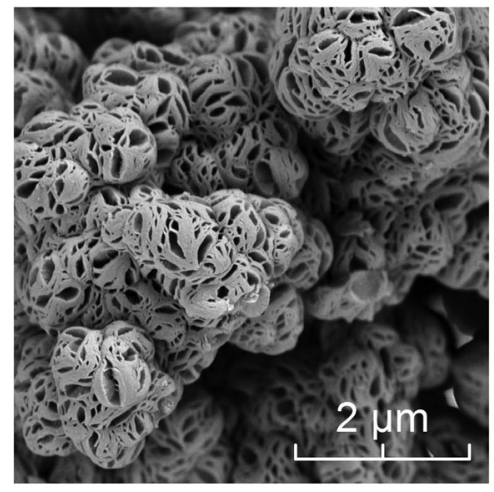

HMS

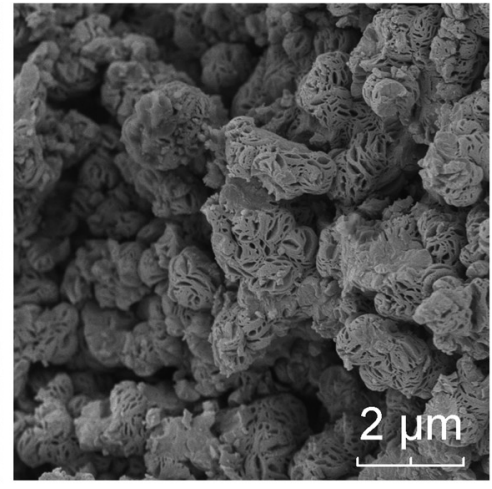

Fe-HMSimp

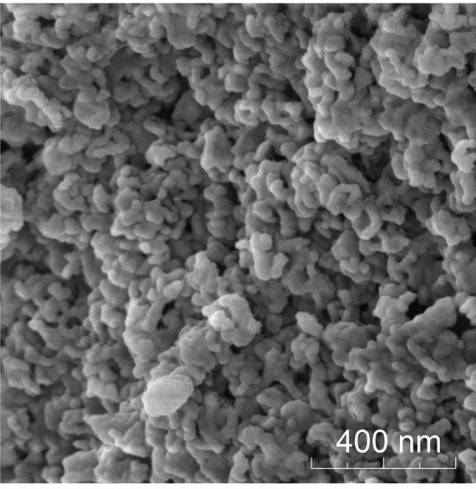

[Fe]-HMS

Fig. 4 SEM micrographs of Fe-HMS samples. 


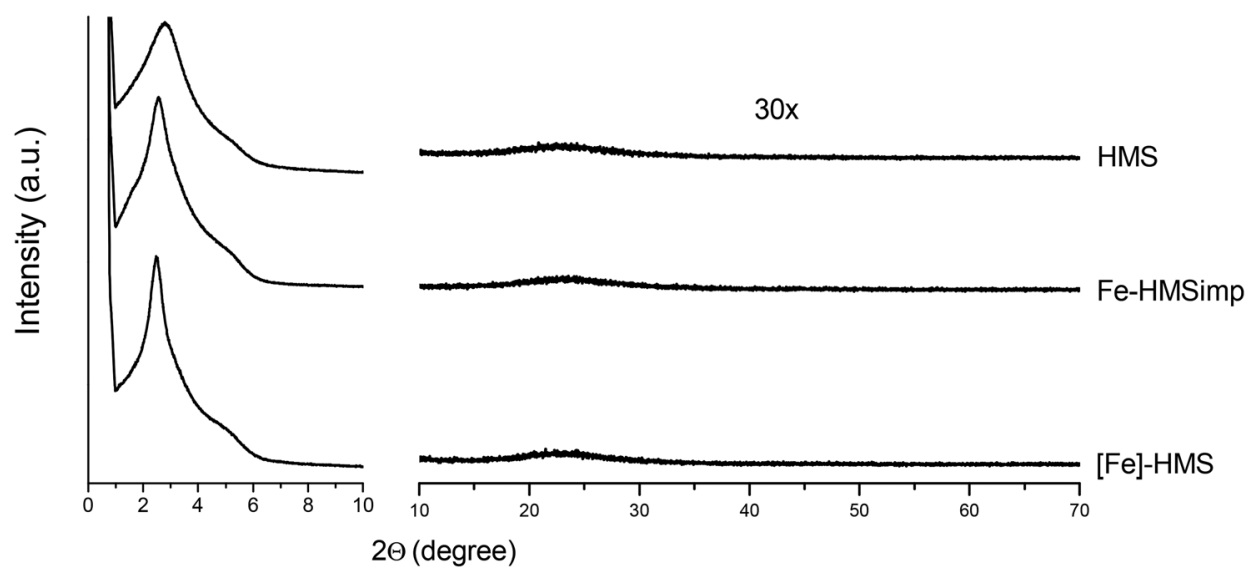

Fig. 5 XRD patterns of HMS samples.
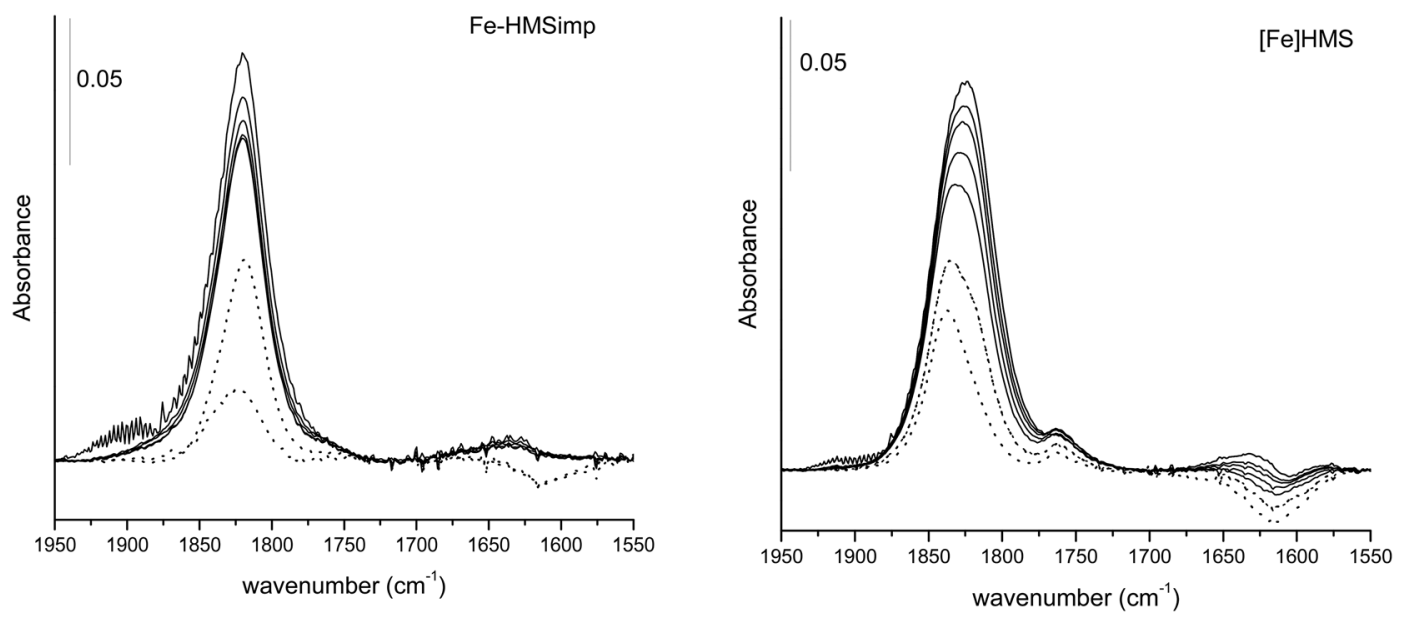

Fig. 6 FTIR spectra of [Fe]-HMS and Fe-HMSimp, desorption of NO with time. The first full line spectrum on the top was collected immediately after the start of desorption, the last full line spectrum at $50 \mathrm{~min}$ of desorption, the dotted line spectra were collected after 1 and 10 min of desorption at $100{ }^{\circ} \mathrm{C}$

(A)

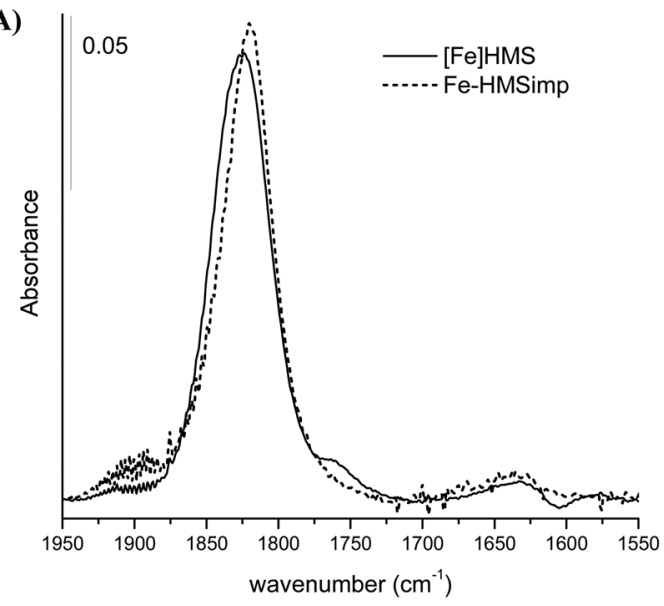

(B)

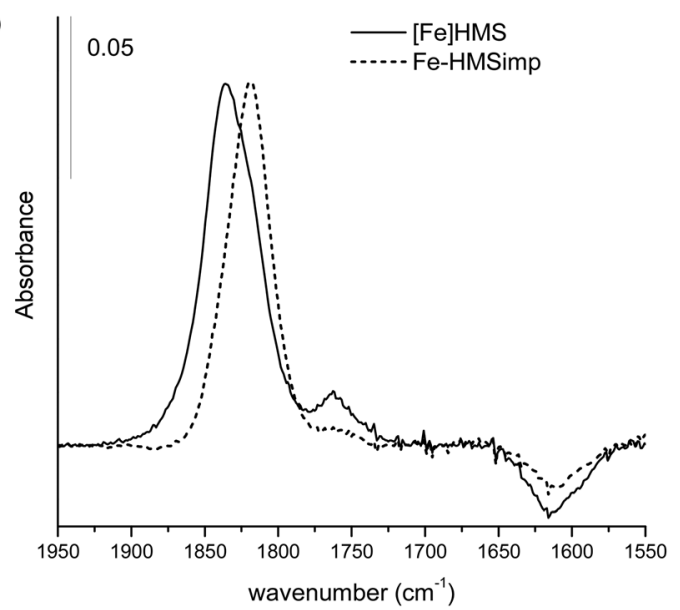

Fig. 7 Comparison of the adsorption spectra of [Fe]-HMS and Fe-HMSimp. (A) Spectra of the samples after the start of desorption at RT, (B) spectra recorded during the desorption at $100{ }^{\circ} \mathrm{C}$, shown spectra correspond to half of the initial value of the intensity of the desorption spectra at RT. 

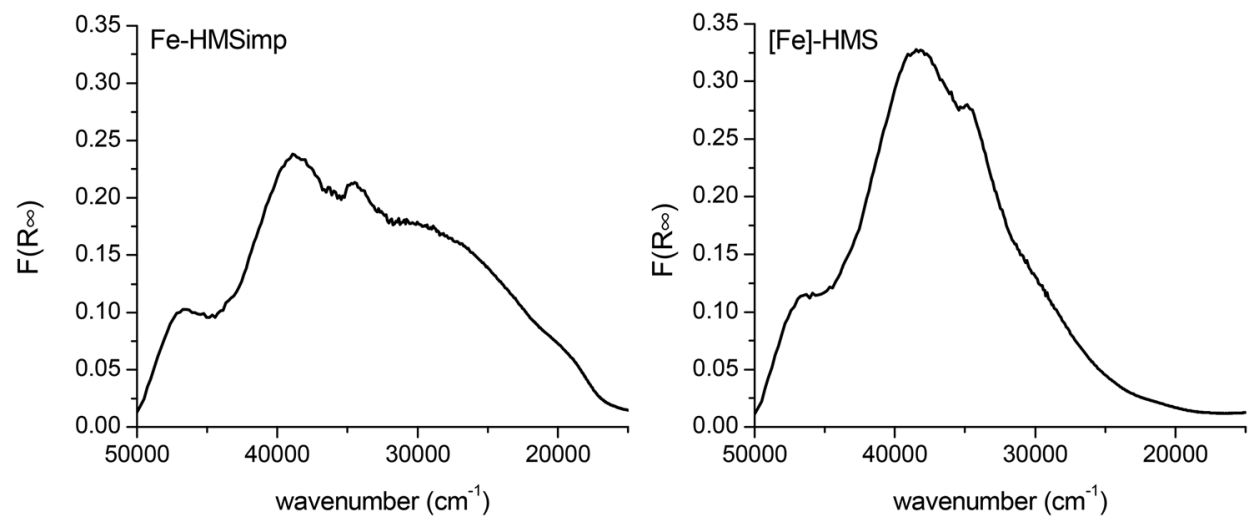

Fig. 8 UV-Vis spectra of hydrated HMS samples.

subsequently at $100{ }^{\circ} \mathrm{C}$ was investigated too. It is evident that the adsorption species are quite stable at RT and the intensity of the bands decreases very slowly in time (approximately 30\% of NO was desorbed during the first 45 minutes under vacuum by turbomolecular pump). Not only intensity, but also shape of the band was changing during desorption. As can be seen from the spectra in Fig. 6 , the band at $1820 \mathrm{~cm}^{-1}$ decreases in intensity faster than the band at $1836 \mathrm{~cm}^{-1}$. The spectra of the samples measured at coverage of the samples of about half of the initial value (Fig. 7B) clearly show that the band at $1836 \mathrm{~cm}^{-1}$ dominates in the case of sample [Fe]-HMS, whereas the impregnated sample is still characterized by a band centered at $1820 \mathrm{~cm}^{-1}$. Therefore, we can conclude that both samples differ in nature of Fe species; the synthesized sample exhibits a much higher population of species characterized by IR band at $1836 \mathrm{~cm}^{-1}$ than the impregnated sample. At a lower coverage degree, a small and relatively broad band at about $1760 \mathrm{~cm}^{-1}$ is detected in the spectra of [Fe]-HMS. A band with similar position and stability was observed in the spectra of $\mathrm{NO}$ adsorbed on $\mathrm{Fe}-\mathrm{Y}$ systems and ascribed to bent species. ${ }^{23}$ It is worth noticing that spectra similar to ours were not described in the literature up to now. We can conclude based on the stability of the band that it corresponds to mononitrosyl species on $\mathrm{Fe}^{2+}$ ions. Surprisingly, no dinitrosyls were observed in the spectra (very often detected in the $\mathrm{Fe}^{2+}$-silica or $\mathrm{Fe}^{2+}$ zeolite systems and reflected by pair of bands at 1920-1900 and $1815-1790 \mathrm{~cm}^{-1}$ ).

The samples were characterized by UV-Vis spectroscopy in order to get information about the iron coordination in the individual samples. The measured reflectivities were converted to Kubelka-Munk units. The spectra are shown in Fig. 8. Both samples are characterized by the absorption bands centered at 46000 and $41000 \mathrm{~cm}^{-1}$ and absorption shoulder at about $35000 \mathrm{~cm}^{-1}$. There is a broad shoulder observable in the region of 30000 to $23000 \mathrm{~cm}^{-1}$. In the region below $20000 \mathrm{~cm}^{-1}$ there is another absorption band very well distinguishable in the case of the impregnated sample. The first two absorption bands at 46000 and $41000 \mathrm{~cm}^{-1}$ correspond to oxygen to metal charge transfer involving isolated ferric cations. These isolated iron ions can originate from isomorphously substituted iron ions in the framework of the materials, as was observed in the case of Fe-silicalite, ${ }^{27}$ or isolated extra-framework ions. ${ }^{6,28}$ The shoulder at $35000 \mathrm{~cm}^{-1}$ should also correspond to isolated iron species. According to the literature it is difficult to distinguish whether these isolated $\mathrm{Fe}^{3+}$ species are in tetrahedral or higher coordination. ${ }^{29}$ However in the literature it has been described that the absorption band at about $35000 \mathrm{~cm}^{-1}$ is caused by $\mathrm{Fe}^{3+}$ in octahedral coordination. $^{27,30}$ The broad absorption band below $30000 \mathrm{~cm}^{-1}$ is caused by small oligonuclear clusters $\left(\mathrm{Fe}^{3+}{ }_{x} \mathrm{O}_{y}\right)^{6}$ and finally the absorption band below $20000 \mathrm{~cm}^{-1}$ is caused by bulky clustered $\mathrm{Fe}_{2} \mathrm{O}_{3}$. species. $^{31}$

More detailed information about the dispersion and local coordination structure of iron species can be obtained from UV-Vis spectroscopy by evaluation of the absorption edge energy $\left(E_{\mathrm{g}}\right)$ from Tauc's plot (the dependency of $\left(F\left(R_{\infty}\right) \cdot h \nu\right)^{2}$ against $h \nu$, where $F\left(R_{\infty}\right)$ is Kubelka-Munk function, $h$ is Planck constant and $\nu$ is frequency of photon). ${ }^{32} E_{\mathrm{g}}$ can be determined from the Tauc's law: $\left(\left(F\left(R_{\infty}\right) \cdot h \nu\right)^{2}\right.$ is proportional to $\left.\left(h \nu-E_{\mathrm{g}}\right)\right)$. Basically, the higher is the calculated value of the absorption band energy the higher is the dispersion of metal in the system. The calculated values of the $E_{\mathrm{g}}$ of Fe catalysts together with the $E_{\mathrm{g}}$ values of standard compound (diluted in the same manner as the studied HMS materials) are listed in Table 2. The $E_{\mathrm{g}}$ value of [Fe]-HMS sample is $3.83 \mathrm{eV}$. Similar values have been already observed by Zhang et al. studying FeMCM-41 prepared by impregnation and by template ion exchange..$^{33}$ On the basis of the correlation of the results from EXAFS and XANES measurement they suggested that the values of the band energy about $4 \mathrm{eV}$ corresponds to small $\mathrm{FeO}_{x}$ clusters with iron in octahedral coordination. The

Table 2 Comparison of absorption band energy for the studied samples

\begin{tabular}{lc}
\hline Material & $E_{\mathrm{g}}(\mathrm{eV})$ \\
\hline $\mathrm{Fe}-\mathrm{HMSimp}$ & 2.00 \\
{$[\mathrm{Fe}]-\mathrm{HMS}$} & 3.83 \\
$\mathrm{Fe}_{2} \mathrm{O}_{3}-\mathrm{SiO}_{2}$ & 2.11
\end{tabular}


impregnated sample exhibits a significantly lower $E_{\mathrm{g}}$ value $(2.00 \mathrm{eV})$. Similar values were also found for various samples by other authors ${ }^{33-35}$ in the case of presence oxide species. In agreement with this statement, model oxides compound $\left(\mathrm{Fe}_{2} \mathrm{O}_{3}-\mathrm{SiO}_{2}\right)$ exhibits also very low $E_{\mathrm{g}}$ value $(2.11 \mathrm{eV})$. Therefore, we can conclude that the catalyst prepared by direct synthesis contains mainly (besides isolated Fe cations) octahedral $\mathrm{FeO}_{x}$ clusters with a small degree of polymerization, whereas the impregnated one contains substantial amount of oxide species.

\subsection{Catalysis}

The main products of the direct ammoxidation of propane were acrylonitrile (ACN), propylene, acetonitrile (AcCN), carbon oxides and ethane.

Fig. 9 shows the comparison of the catalytic performance of the Fe-HMS samples. The conversion of propane reaches very similar values; a slightly higher conversion is obtained over the sample prepared by direct synthesis $(11 \%$ vs. $9 \%$ for the sample Fe-HMSimp). Consumption of oxygen is also similar (about $42 \%$ of oxygen), conversion of ammonia reaches higher values over the impregnated sample (60 vs. 51\%). Selectivity to ACN varies a lot, the sample prepared by direct synthesis reached twice as high selectivity to ACN compared to the impregnated sample. Selectivity to propylene is higher in the case of the impregnated sample (33 vs. 23\%), so is the selectivity to carbon oxide, the difference is twice as much (35 vs. $16 \%$ ). These results clearly demonstrate that impregnation of silica does not lead to selective catalytic system. This is in accordance with the results from UV-Vis spectroscopy; the impregnated sample showed high concentration of bulky clustered $\mathrm{Fe}_{2} \mathrm{O}_{3}$ species.

Fig. 10 shows selectivity to ACN-conversion of propane relationship for the sample [Fe]-HMS and Fe-HMSimp in comparison to microporous Fe-silicalite. As can be seen from the graph, there are pronounced differences regarding the selectivities to ACN. At very similar conversion of propane $(15 \%)$, the sample prepared by direct synthesis reaches higher selectivity

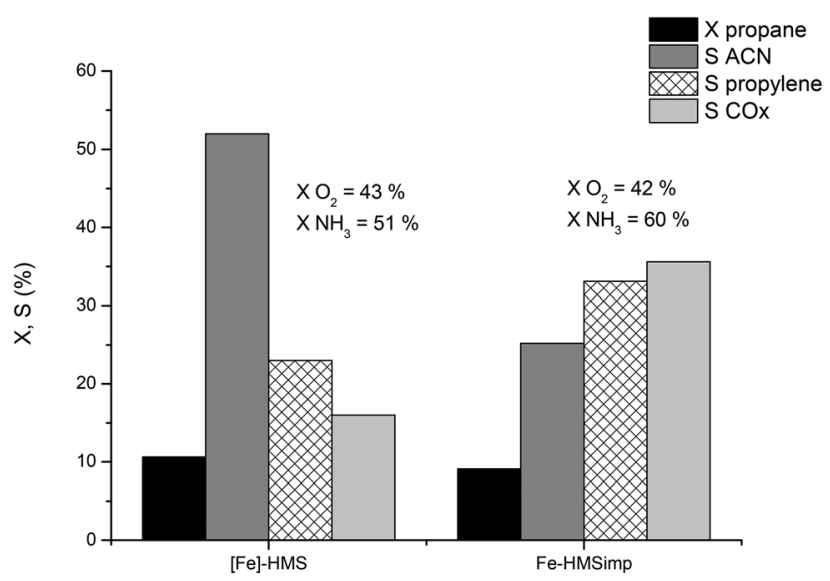

Fig. 9 Comparison of the catalytic activity of the impregnated Fe-HMS samples together with [Fe]-HMS in the direct ammoxidation of propane.

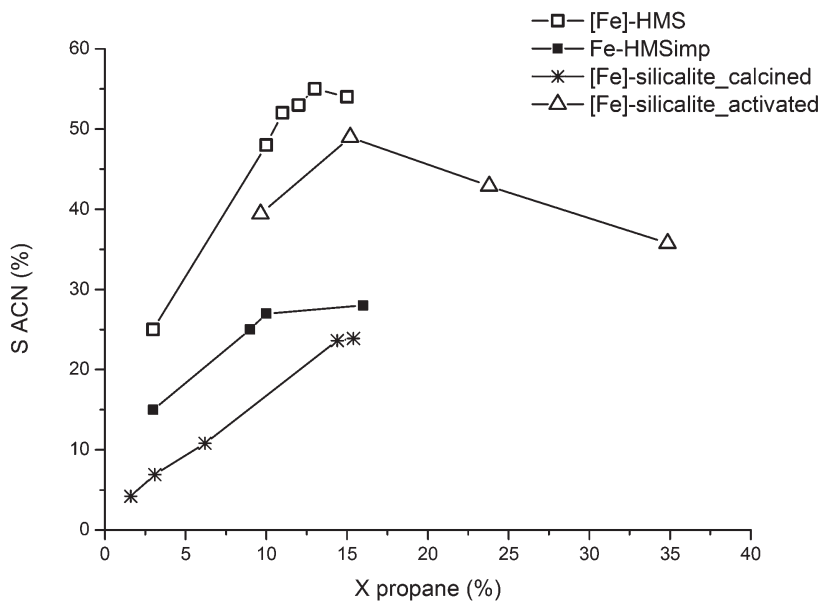

Fig. 10 Selectivity-conversion relationship for the samples [Fe]-HMS, Fe-HMSimp in comparison with Fe-silicalite samples, calcined and activated in the direct ammoxidation of propane.

to ACN (twice as much) compared to the impregnated sample. Very interesting is the comparison of mesoporous materials with microporous Fe-silicalite with concentration of iron 0.48 wt $\%$. This material, as it has been shown previously, ${ }^{19}$ showed quite interesting results in the direct ammoxidation of propane, good results were obtained over the sample which was activated in the diluted stream of propane and ammonia. As it is evident from the figure, at a similar conversion of propane, the calcined mesoporous material was more selective than the calcined Fe-silicalite. Activated Fe-silicalite reached very similar selectivity to ACN as iron doped mesoporous material prepared by direct synthesis.

Another comparison of the catalytic activity of microporous and mesoporous systems can be given by expressing the productivity of the catalyst and turn over frequencies, see Table 3. Regarding the TOF it can be clearly seen that activated microporous material reaches the best results, however comparing the productivities we see that the mesoporous material [Fe]HMS is able to give good results in comparison to calcined microporous Fe-silicalite. This is quite interesting mainly by taking into account the other studies from the literature dealing with $\mathrm{N}_{2} \mathrm{O}$ mediated $\mathrm{ODH}$ of propane, ${ }^{28,36}$ where it has been stated that microporous materials reach better results then the mesoporous ones. It has been proposed that it is due to the lack of the intimate contact between potentially active Fe sites and reactant molecules, ${ }^{28}$ another assumption was that the chemical nature of iron sites is more important than the pore structure. ${ }^{36}$

On the basis of our results from characterization techniques (UV-Vis) and from catalytic studies we tend to agree with the opinion that the nature of the iron sites is the key factor influencing the catalytic properties. Our study showed that use of the same matrix (HMS) but different method of iron incorporation leads to material with different catalytic properties. The impregnated sample contains only extra-framework Fe species with high heterogeneity covering species from 
Table 3 Comparison of catalytic activity of mesoporous Fe-HMS and microporous Fe-silicalite

\begin{tabular}{lllrrrr}
\hline Material & Fe $(\mathrm{wt} \%)$ & $W / F_{\text {(propane) }}\left(\mathrm{kg} \mathrm{h} \mathrm{mol}^{-1}\right)$ & $X_{\text {propane }}(\%)$ & $S_{\mathrm{ACN}}(\%)$ & $P\left(\mathrm{~mol} \mathrm{~kg}^{-1} \mathrm{~h}^{-1}\right)$ & $\left.\mathrm{TOF}^{-1} \mathrm{~h}^{-1}\right)$ \\
\hline Fe-HMSimp & 0.54 & 0.015 & 9 & 25 & 1.5 \\
[Fe-HMS & 0.95 & 0.0084 & 11 & 52 & 6.6 \\
Fe-silicalite_calc & 0.48 & 0.012 & 5 & 5 & 0.3 & 75 \\
Fe-silicalite_act & 0.43 & 0.012 & 25 & 44 & 9.3 & 45
\end{tabular}

isolated Fe ions to oxidic nanoparticles. The synthesized sample could contain both framework and extra-framework species. Isolated Fe species, represented in the UV-vis spectra by absorption bands at 46000 and $41000 \mathrm{~cm}^{-1}$, can originate from isomorphously substituted iron ions in the framework of the materials or isolated extra-framework ions. However, it is not possible to distinguish between these two forms of isolated Fe cations directly from UV-Vis spectra. Framework Fe species could be distinguished by UV Raman spectroscopy ${ }^{37}$ by vibrational bands at 510 and $1090 \mathrm{~cm}^{-1}$ assigned to the symmetric and asymmetric Fe-O-Si stretching modes of the amorphous silica framework. On the other hand, we proved the presence of extra-framework Fe species in the synthesized sample by FT-IR spectra of adsorbed NO. Our previous studies conducted on Fe-silicalites clearly showed that extraction of $\mathrm{Fe}$ species from the framework is essential for reaching high catalytic activity in propane ammoxidation. ${ }^{18,19}$ Therefore, we deduced that framework Fe atoms cannot act as an active site. We are aware that framework of amorphous mesoporous silica is more flexible than the zeolitic structure which can change the properties of tetrahedral atoms in the framework. However we believe that extra-framework species are much more active species and the catalytic performance of the catalyst is given by presence of such particles. This has been already proposed in the literature by numerous studies dealing with the investigation of the catalytic behaviour of iron doped micro- and meso-porous materials in various reactions, including hydroxylation of benzene to phenol, ${ }^{38,39}$ SCR or decomposition of $\mathrm{N}_{2} \mathrm{O},{ }^{40,41} \mathrm{ODH}$ of propane ${ }^{42,43}$ and also in the direct ammoxidation of propane. ${ }^{17}$ Unfortunately, extra-framework Fe particles exhibit high level of heterogeneity and discovering active Fe particle is a very challenging task.

\section{Conclusion}

The direct synthesis procedure reported in this paper led to the mesoporous material with considerably larger total pore volume, surface area exceeding $1000 \mathrm{~m}^{2} \mathrm{~g}^{-1}$ and exhibiting nano-crystallites of $20-30 \mathrm{~nm}$ in size facilitating mass transport and diffusion of reactant and products. The direct synthesis of Fe-mesoporous silica led to better dispersion of iron in the material compared with impregnation procedures. This had the positive effect on the catalytic activity of the materials, as it has been shown, that over [Fe]-HMS quite high selectivity to acrylonitrile was achieved, meanwhile the impregnated sample gave high selectivity to carbon oxides. Catalytic activity and selectivity of the [Fe]-HMS catalyst, able to compete with
Fe-MFI zeolites, was reached without any special activation (the sample was only calcined to the reaction temperature in the air), whereas the most active and selective Fe-silicalite zeolite was activated by reductive nitridation in the flow of ammonia and propane at reaction temperature for relative long time (from 5 to $15 \mathrm{~h}$ ).

\section{Acknowledgements}

Financial support of the Czech Science Foundation under project Nos. P106/12/P083 (KR) and P106/12/G015 (RB) and Ministry of Education under the UniCRE project (CZ.1.05/ 2.1.00/03.0071) (EB) is highly acknowledged. The authors are very thankful to TESCAN, a.s. for performing SEM analysis.

\section{References}

1 E. J. M. Hensen, Q. Zhu and R. A. van Santen, J. Catal., 2003, 220, 260-264.

2 G. I. Panov, G. A. Sheveleva, A. S. Kharitonov, V. N. Romannikov and L. A. Vostrikova, Appl. Catal., A, 1992, 82, 31-36.

3 R. Leanza, I. Rossetti, I. Mazzola and L. Forni, Appl. Catal., A, 2001, 205, 93-99.

4 A. Shishkin, P. A. Carlsson, H. Harelind and M. Skoglundh, Top. Catal., 2013, 56, 567-575.

5 D. E. Doronkin, L. V. Piryutko, E. V. Starokon, G. I. Panov and A. Y. Stakheev, Kinet. Catal., 2012, 53, 747-752.

6 M. Schwidder, M. S. Kumar, K. Klementiev, M. M. Pohl, A. Bruckner and W. Grunert, J. Catal., 2005, 231, 314-330.

7 G. S. Qi and R. T. Yang, Appl. Catal., B, 2005, 60, 13-22.

8 M. Iwasaki, K. Yamazaki, K. Banno and H. Shinjoh, J. Catal., 2008, 260, 205-216.

9 R. Q. Long and R. T. Yang, J. Catal., 2000, 194, 80-90.

10 Q. Xiao, F. F. Yang, J. Zhuang, G. P. Qiu, Y. J. Zhong and W. D. Zhu, Microporous Mesoporous Mater., 2013, 167, 3843.

11 Q. H. Guo, B. H. Chen, Y. X. Li and J. W. Li, Catal. Lett., 2008, 120, 65-70.

12 B. J. Schoeman, J. Sterte and J. E. Otterstedt, J. Chem. Soc., Chem. Commun., 1993, 994-995.

13 M. E. Davis, C. Saldarriaga, C. Montes, J. Garces and C. Crowder, Nature, 1988, 331, 698-699.

14 D. Verboekend, R. Caicedo-Realpe, A. Bonilla, M. Santiago and J. Perez-Ramirez, Chem. Mater., 2010, 22, 4679-4689. 
15 J. Perez-Ramirez, C. H. Christensen, K. Egeblad and J. C. Groen, Chem. Soc. Rev., 2008, 37, 2530-2542.

16 J. Perez-Ramirez, D. Verboekend, A. Bonilla and S. Abello, Adv. Funct. Mater., 2009, 19, 3972-3979.

17 R. Bulanek and F. Castek, Top. Catal., 2007, 45, 233237.

18 R. Bulanek, K. Raabova, G. Kosova-Kucerova and L. Capek, in Zeolites and Related Materials: Trends, Targets and Challenges, Proceedings of the 4th International Feza Conference, ed. A. Gedeon, P. Massiani and F. Babonneau, 2008, vol. 174, pp. 1151-1154.

19 R. Bulanek, K. Raabova and E. Bad'urova, Catal. Today, 2012, 179, 73-77.

20 A. Jentys, N. H. Pham and H. Vinek, J. Chem. Soc., Faraday Trans., 1996, 92, 3287-3291.

21 R. Bulanek, A. Kaluzova, M. Setnicka, A. Zukal, P. Cicmanec and J. Mayerova, Catal. Today, 2012, 179, 149158.

22 H. Liu, G. Z. Lu, Y. L. Guo, Y. Guo and J. S. Wang, Nanotechnology, 2006, 17, 997-1003.

23 K. Segawa, Y. Chen, J. E. Kubsh, W. N. Delgass, J. A. Dumesic and W. K. Hall, J. Catal., 1982, 76, 112-132.

24 B. Gil and A. Adamski, Microporous Mesoporous Mater., 2010, 127, 82-89.

25 G. Berlier, G. Spoto, S. Bordiga, G. Ricchiardi, P. Fisicaro, A. Zecchina, I. Rossetti, E. Selli, L. Forni, E. Giamello and C. Lamberti, J. Catal., 2002, 208, 64-82.

26 K. I. Hadjiivanov, Catal. Rev. Sci. Eng., 2000, 42, 71-144.

27 S. Bordiga, R. Buzzoni, F. Geobaldo, C. Lamberti, E. Giamello, A. Zecchina, G. Leofanti, G. Petrini, G. Tozzola and G. Vlaic, J. Catal., 1996, 158, 486-501.

28 A. S. Kumar, J. Perez-Ramirez, M. N. Debbagh, B. Smarsly, U. Bentrup and A. Bruckner, Appl. Catal., B, 2006, 62, 244254.
29 J. Perez-Ramirez, M. S. Kumar and A. Bruckner, J. Catal., 2004, 223, 13-27.

30 G. Centi, S. Perathoner, F. Pino, R. Arrigo, G. Giordano, A. Katovic and V. Pedula, Catal. Today, 2005, 110, 211-220.

31 E. J. M. Hensen, Q. Zhu, M. Hendrix, A. R. Overweg, P. J. Kooyman, M. V. Sychev and R. A. van Santen, J. Catal., 2004, 221, 560-574.

32 J. Tauc, Amorphous and Liquid Semiconductors, Plenum Press, London, 1974.

33 Q. H. Zhang, Q. Guo, X. X. Wang, T. Shishido and Y. Wang, J. Catal., 2006, 239, 105-116.

34 J. V. Coelho, M. S. Guedes, D. Barrera, K. Sapag, M. C. Pereira and L. C. A. d. Oliveira, Dalton Trans., 2013, 42, 11271-11280.

35 M. Iwamoto, T. Abe and Y. Tachibana, J. Mol. Catal. A: Chem., 2000, 155, 143-153.

36 W. Wei, J. A. Moulijn and G. Mul, J. Catal., 2009, 262, 1-8.

37 F. Fan, Z. Feng and C. Li, Acc. Chem. Res., 2010, 43, 378387.

38 D. Meloni, R. Monaci, V. Solinas, G. Berlier, S. Bordiga, I. Rossetti, C. Oliva and L. Forni, J. Catal., 2003, 214, 169178.

39 Y. Li, H. Xia, F. Fan, Z. Feng, R. A. van Santen, E. J. M. Hensen and C. Li, Chem. Commun., 2008, 774-776.

40 V. I. Sobolev, G. I. Panov, A. S. Kharitonov, V. N. Romannikov, A. M. Volodin and K. G. Ione, J. Catal., 1993, 139, 435-443.

41 J. Perez-Ramirez, J. C. Groen, A. Bruckner, M. S. Kumar, U. Bentrup, M. N. Debbagh and L. A. Villaescusa, J. Catal., 2005, 232, 318-334.

42 R. Bulanek, B. Wichterlova, K. Novoveska and V. Kreibich, Appl. Catal., A, 2004, 264, 13-22.

43 J. Perez-Ramirez and A. Gallardo-Llamas, Appl. Catal., A, 2005, 279, 117-123. 